\title{
Correction to: The adjoint Newton algorithm for large-scale unconstrained optimization in meteorology applications
}

\author{
Zhi Wang $^{1} \cdot$ K. Droegemeier ${ }^{1} \cdot$ L. White ${ }^{2}$
}

Published online: 20 April 2019

○) Springer Science+Business Media, LLC, part of Springer Nature 2019

\section{Correction to: Computational Optimization and Applications 10, 283-320 (1998) https://doi.org/10.1023/A:1018321307393}

It has come to our attention that the "Adjoint Newton Algorithm" has been published within the following papers

Wang, Z., Droegemeier, K.K., White, L. \& Navon, I.M. Monthly Weather Review (1997) 125: 2460. https://doi.org/10.1175/1520-0493

and

Wang, Z., Droegemeier, K. \& White, L. Computational Optimization and Applications (1998) 10: 283. https://doi.org/10.1023/A:1018321307393

The authors acknowledge that Wang et al. (1998) was submitted two years prior to publication and was therefore intended to precede Wang et al. (1997), and they acknowledge that Wang et al. (1997) was the first to publish the algorithm.

Publisher's Note Springer Nature remains neutral with regard to jurisdictional claims in published maps and institutional affiliations.

The original article can be found online at https://doi.org/10.1023/A:1018321307393.

K. Droegemeier

kkd@ou.edu

1 Center for Analysis and Prediction of Storms and School of Meteorology, University of Oklahoma, Norman, OK 73019, USA

2 Department of Mathematics, University of Oklahoma, Norman, USA 